\title{
Dynamics of Propofol-Induced Loss of Consciousness Across Primate Neocortex
}

\author{
다 umiko Ishizawa, ${ }^{1}$ Omar J. Ahmed, ${ }^{2}$ Shaun R. Patel, ${ }^{3}$ John T. Gale, ${ }^{3}$ Demetrio Sierra-Mercado, ${ }^{3}$ Emery N. Brown, ${ }^{1,4,5}$ \\ and Emad N. Eskandar ${ }^{3}$ \\ ${ }^{1}$ Department of Anesthesia, Critical Care and Pain Medicine, ${ }^{2}$ Department of Neurology, and ${ }^{3}$ Department of Neurosurgery, Massachusetts General \\ Hospital, Harvard Medical School, Boston, Massachusetts 02114, and ${ }^{4}$ Institute for Medical Engineering and Science and ${ }^{5}$ Department of Brain and \\ Cognitive Sciences, Massachusetts Institute of Technology, Cambridge, Massachusetts 02139
}

The precise neural mechanisms underlying transitions between consciousness and anesthetic-induced unconsciousness remain unclear. Here, we studied intracortical neuronal dynamics leading to propofol-induced unconsciousness by recording single-neuron activity and local field potentials directly in the functionally interconnecting somatosensory (S1) and frontal ventral premotor (PMv) network during a gradual behavioral transition from full alertness to loss of consciousness (LOC) and on through a deeper anesthetic level. Macaque monkeys were trained for a behavioral task designed to determine the trial-by-trial alertness and neuronal response to tactile and auditory stimulation. We show that disruption of coherent beta oscillations between $\mathrm{S} 1$ and PMv preceded, but did not coincide with, the LOC. LOC appeared to correspond to pronounced but brief gamma-/high-beta-band oscillations (lasting $\sim 3 \mathrm{~min}$ ) in PMv, followed by a gamma peak in S1. We also demonstrate that the slow oscillations appeared after LOC in S1 and then in PMv after a delay, together suggesting that neuronal dynamics are very different across S1 versus PMv during LOC. Finally, neurons in both S1 and PMv transition from responding to bimodal (tactile and auditory) stimulation before LOC to only tactile modality during unconsciousness, consistent with an inhibition of multisensory integration in this network. Our results show that propofol-induced LOC is accompanied by spatiotemporally distinct oscillatory neuronal dynamics across the somatosensory and premotor network and suggest that a transitional state from wakefulness to unconsciousness is not a continuous process, but rather a series of discrete neural changes.

Key words: general anesthesia; local field potential; loss of consciousness; primate; sensory premotor network; single-neuron activity

Significance Statement

How information is processed by the brain during awake and anesthetized states and, crucially, during the transition is not clearly understood. We demonstrate that neuronal dynamics are very different within an interconnecting cortical network (primary somatosensory and frontal premotor area) during the loss of consciousness (LOC) induced by propofol in nonhuman primates. Coherent beta oscillations between these regions are disrupted before LOC. Pronounced but brief gamma-band oscillations appear to correspond to LOC. In addition, neurons in both of these cortices transition from responding to both tactile and auditory stimulation before LOC to only tactile modality during unconsciousness. We demonstrate that propofol-induced LOC is accompanied by spatiotemporally distinctive neuronal dynamics in this network with concurrent changes in multisensory processing.

\section{Introduction}

Understanding of the neurophysiological state of the brain under general anesthesia has been greatly advanced by recent electro- encephalography (EEG) and neuroimaging studies (John and Prichep, 2005; Alkire et al., 2008; Brown et al., 2010; Brown et al., 2011; Hudetz, 2012). Anesthetic-induced unconsciousness is

\footnotetext{
Received Dec. 18, 2015; revised May 30, 2016; accepted June 1, 2016.

Author contributions: Y.I., J.T.G., E.N.B., and E.N.E. designed research; Y.I., S.R.P., J.T.G., D.S.-M., and E.N.E. performed research; Y.I., O.J.A., and S.R.P. analyzed data; Y.I., O.J.A., and S.R.P. wrote the paper.

This work was supported by the Foundation for Anesthesia Education and Research, the National Institutes of Health (Grant 5T32GM007592), and Harvard Medical School (Eleanor and Miles Shore 50th Anniversary Fellowship Scholars in Medicine). We thank T. Kawai, C.-S. Kwon, F. Girgis, M. K. Mian, and S. Abdel-Aziz for help with primate surgeries; A. Uchida for assistance in animal experiments; and W.M. Zapol for expert advice.

The authors declare no competing financial interests.
}

0.J. Ahmed's present address: Department of Psychology and Program in Neuroscience, University of Michigan, Ann Arbor, MI 48109.

J.T. Gale's present address: Department of Neurosciences, The Cleveland Clinic Foundation, Cleveland, $0 \mathrm{H} 44195$. D. Sierra-Mercado's present address: Department of Anatomy and Neurobiology, University of Puerto Rico School of Medicine, San Juan, Puerto Rico 00936.

Corresponding author: Yumiko Ishizawa, Department of Anesthesia, Critical Care and Pain Medicine, Massachusetts General Hospital, Harvard Medical School, 55 Fruit Street, Boston, MA 02114. E-mail: yishizawa@mgh.harvard.edu.

DOI:10.1523/JNEUROSCI.4577-15.2016

Copyright $\odot 2016$ the authors $\quad 0270-6474 / 16 / 367718-09 \$ 15.00 / 0$ 
now thought to be associated with profound oscillations between brain structures (Ching et al., 2010; Cimenser et al., 2011; Lewis et al., 2012; Purdon et al., 2013; Akeju et al., 2014). Human EEG studies show predictable, signature changes during anestheticinduced unconsciousness (Purdon et al., 2013). However, local field potentials (LFPs) and EEG signals are often decoupled due to a variety of electrophysiological and anatomical variables (Musall et al., 2014). A widely used EEG monitor failed to reduce the incidence of intraoperative awareness (Avidan et al., 2011), highlighting the potential lack of sensitivity in EEG. Despite the importance of understanding the intracortical neuronal dynamics associated with anesthetic-induced unconsciousness, direct recordings from neocortex, especially functionally interconnecting regions, during anesthesia are rare in primates. Moreover, the neurophysiological changes during the transition between consciousness and unconsciousness have not been well characterized.

Human neuroimaging studies suggested that higher-order cortical areas that support cognitive processes are more sensitive to general anesthetics compared with the primary sensory cortices (Heinke and Schwarzbauer, 2001; Heinke et al., 2004). General anesthetics may disrupt cortical integration of incoming information. An intravenous anesthetic propofol is thought to induce inhibition by potentiating $\mathrm{GABA}_{\mathrm{A}}$ receptor-mediated inhibition of pyramidal neurons (Brown et al., 2010; Brown et al., 2011). Propofol therefore enhances hyperpolarization of these neurons (Hanrahan et al., 2013), consistent with an increase in the slow oscillations and a decrease in the spike firing rate observed in our study. A recent human study showed that connectivity between distant cortical areas was disrupted under propofol (Lewis et al., 2012). However, how incoming information is processed has not been shown previously in a functionally interconnecting neocortical network. Further, whether propofol modulates neurons differently in primary sensory cortices and higher-order cognitive areas is not known.

Here, we hypothesized that a transition to propofol-induced unconsciousness is associated with disruption of regional interaction in a primary sensory and higher-order cortical network in primates. We further hypothesized that sensory information transfer is disrupted in the hierarchical network and the sensory responses of higher-order neurons are more diminished than that of the primary sensory neurons. To investigate these hypotheses, we have developed a primate model in which direct intracortical recording was performed in the functionally interconnecting somatosensory and frontal premotor network (the primary and secondary somatosensory cortex, S1 and S2, and the ventral premotor area, PMv), a well studied corticocortical circuit (de Lafuente and Romo, 2006), during transition from full alertness to propofol-induced loss of consciousness (LOC). The PMv is known to have cognitive functions and multisensory integration (Rizzolatti et al., 2002; Romo et al., 2004; de Lafuente and Romo, 2006; Lemus et al., 2009; Acuña et al., 2010). Functional homology of this network has been shown between nonhuman primates and humans (Rizzolatti et al., 2002). Our data show that disruption of beta coherence in this network preceded, but did not coincide with, the LOC. LOC appeared to correspond to a brief peak of gamma/high-beta oscillations in PMv, which was followed by a gamma peak in S1. The slow oscillations started to increase after LOC in S1 and then in PMv after a delay. Together, our results suggest that neuronal dynamics are very different across primary somatosensory versus frontal premotor cortex, including regionand frequency-specific changes. Moreover, propofol appeared to di- minish sensory responses similarly in the $\mathrm{S} 1$ and PMv neurons, but interrupted auditory processing preferentially, consistent with an inhibition of multisensory integration.

\section{Materials and Methods}

Animal model. All animals were handled according to the institutional standards of the National Institutes of Health and according to an animal protocol approved by the institutional animal care and use committee at the Massachusetts General Hospital. We used two adult male monkeys (Macaca mulatta, 10-12 kg). Before starting the study, a titanium head post was surgically implanted on each animal. A vascular access port was also surgically implanted in the internal jugular vein (Model CP6; Access Technologies). Once the animals had mastered the following task, before the recording studies, extracellular microelectrode arrays (Floating Microelectrode Arrays; MicroProbes) were implanted into S1, S2, and PMv through a craniotomy (Fig. $1 A)$. Each array $(1.95 \times 2.5 \mathrm{~mm})$ contained 16 platinum-iridium recording microelectrodes $(\sim 0.5 \mathrm{M} \Omega, 1.5-4.5 \mathrm{~mm}$ staggered length) separated by $400 \mu \mathrm{m}$. The placement of arrays was guided by the landmarks on cortical surface (Fig. $1 A$ ) and stereotaxic coordinates (Saleem and Logothetis, 2012). A total of five arrays were implanted in Monkey E (two arrays in S1, one in S2, and two in PMv in the left hemisphere) and four arrays in Monkey $\mathrm{H}$ (two arrays in S1, one in S2, and one and PMv in the right hemisphere). An S2 array in Monkey $\mathrm{H}$ did not provide stable signals due to unknown damage. The responsiveness to the tactile (air puff) stimulation to the face was tested in single-neuron spikes recorded from all arrays after implantation. The recording experiments were performed after 2 weeks of recovery after the array surgery. All experiments were conducted in the radio-frequencyshielded recording enclosures.

Behavioral task. The animals were trained in the behavioral task shown in Figure $1 B$. After the start tone $(1000 \mathrm{~Hz}, 100 \mathrm{~ms})$, the animals were required to initiate each trial by holding the button located in front of the primate chair using the hand ipsilateral to the recording hemisphere. They were required to keep holding the button until the task end to receive a liquid reward. The monkeys were trained to perform a correct response in $>90 \%$ of the trials consistently for longer than $\sim 1.5 \mathrm{~h}$ in an alert condition. An animal's performance during the session was monitored and simultaneously recorded using a MATLAB-based behavior control system (Asaad and Eskandar, 2008a, 2008b). The trial-by-trial behavioral response was analyzed as a correct response (button holding until the trial end and release), failed attempt (early release, late touch, or no release of the button), or no response (Fig. 1C). LOC was defined as the first no-response trial that was followed by a complete lack of response for the rest of anesthesia.

One of the four sensory stimulus sets was delivered to the animal during trial at a random delay (air puff, sound, simultaneous air puff and sound, no stimulus; Fig. $1 B$ ). Air puffs were delivered at 12 psi to the lower part of the face contralateral to the recording hemisphere via a computer-controlled regulator with a solenoid valve (AirStim; San Diego Instruments). The eye area was avoided from the puff stimulation. Sound stimuli (pure tone at $4000 \mathrm{~Hz}$ at $80 \mathrm{~dB} \mathrm{SPL}$ ) were generated by a computer and delivered using two speakers $40 \mathrm{~cm}$ from the animal. White noise (50 dB SPL) was applied throughout the trial to mask the air puff and mechanical noises. All of the stimulus sets were presented randomly to the animal regardless of their behavioral response throughout the recording session.

Anesthesia. After the $30 \mathrm{~min}$ of awake performance, propofol was infused for $60 \mathrm{~min}$ at a fixed rate $(200 \mu \mathrm{g} / \mathrm{kg} / \mathrm{min}$ for Monkey E, 230 or 270 $\mu \mathrm{g} / \mathrm{kg} / \mathrm{min}$ for Monkey $\mathrm{H}$ ) through a vascular access port. The infusion rate of propofol was determined to induce LOC in $\sim 10 \mathrm{~min}$ for each animal. No other sedatives or anesthetics were used during the experiment. The animal's heart rate and oxygen saturation were monitored continuously throughout the session (CANL-425SV-A Pulse Oximeter; Med Associates). The animals maintained $>94 \%$ oxygen saturation throughout the experiments.

Neurophysiology data recording. Neural activity was recorded continuously and simultaneously from S1, S2, and PMv through the microelectrode arrays while the animals were alert and participating in the task and 
throughout anesthesia and recovery. Analog data were amplified, band-pass filtered between 0.5 and $8 \mathrm{kHz}$, and sampled at $40 \mathrm{kHz}$ (OmniPlex; Plexon). LFPs were separated by low-pass filtering at $200 \mathrm{~Hz}$ and down-sampled at $1 \mathrm{kHz}$. The spiking activity was obtained by high-pass filtering at $300 \mathrm{kHz}$ and a minimum threshold of 3 SDs was applied to exclude background noise from the raw voltage tracings on each channel. Action potentials were sorted using waveform principal component analysis (Offline Sorter; Plexon). Only spikes that were stable through the awake recording period and that demonstrated recovery in the firing rate within a half hour after the termination of propofol infusion were included in the analysis. Task-responsive neurons were categorized based on their sensory response to a puff or sound stimulus into three groups: bimodal puff and sound-responsive, unimodal puffresponsive, or unimodal sound-responsive neurons.

The recordings under propofol anesthesia were performed 18 times in Monkey E and 11 times in Monkey H. In separate sessions, the recordings were performed under propofol in the animals that were required no task performance (two sessions in Monkey E and three sessions in Monkey $\mathrm{H}$ ) and in the blindfolded animals that were performing the task (three sessions in each animal). In addition, multiple recordings were performed in alert performing animals without anesthesia.

Field potential data analysis. All LFP analyses were performed using existing and customwritten functions in MATLAB (The MathWorks). Multitaper spectral analysis of the LFP using the Chronux toolbox for MATLAB was used to generate spectra (Fig. $2 C, D$ ), spectrograms (Fig. 2A,B), and power changes over time (Fig. 2E). Five second time windows were used when generating spectrograms or calculating power changes in a particular band over time. The time bin around LOC with the peak power in each frequency band was extracted and used to generate Figure $2 F$. All coherence calculations were performed with MATLAB's standard signal processing toolbox and used to calculate time-varying changes in coherence at each frequency over $10 \mathrm{~s}$ time bins. These data were then used to generate coherograms (Figs. $3 A-C, 5 A, C, F$ ) and changes in coherence in particular frequency bands over time (Fig. $3 D, E$ ). Spike phase locking was calculated by first using the Hilbert transform to generate the phase of the filtered LFP and then reading this phase at the time when each spike occurred. Circular statistics, based on the von Mises distribution, were then used to calculate the strength of phase locking based on the timevarying $z$-scored $\kappa$ values (Fig. $3 G$ ) (Zar, 1998). Evoked potentials were calculated using the raw, unfiltered LFP and normalized using the baseline LFP over the $200 \mathrm{~ms}$ preceding each stimulus (Fig. 4A,B).

Single-unit data analysis. All single-unit analyses were performed using custom-written software in the MATLAB programming environment using standard signal processing and statistical toolboxes. Peristimulus time histograms (PSTHs) were constructed for each neuron by binning spiking data into $1 \mathrm{~ms}$ bins and convolving a Gaussian function $(\mathrm{SD}=50 \mathrm{~ms})$ during a $4 \mathrm{~s}$ time window centered on the stimulus delivery. Neurons were categorized into three groups (bimodal puff and sound-responsive, unimodal puff-responsive, and unimodal sound-responsive neurons) based on their response to a puff or sound stimulus during wakefulness. On each trial, prestimulus baseline activity was compared against a $500 \mathrm{~ms}$ poststimulus window using a
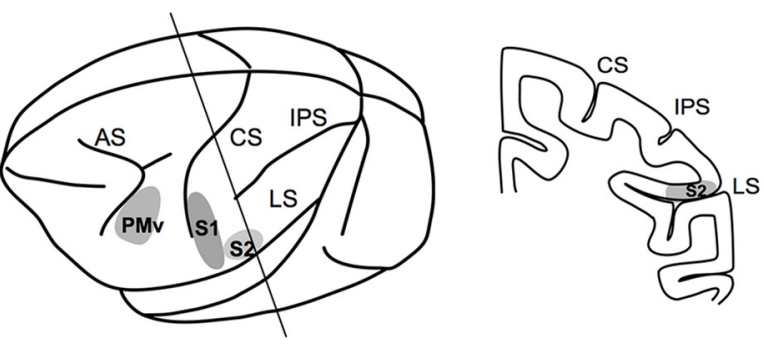

Fecording location, behavioral task, and behavioral response to propofol. $A$, Location of recording sites in $\mathrm{S1}, \mathrm{S2}$, and ipsilateral to the recording hemisphere). The animal is required to keep its hand on the button until the end of the trial to be able gain a liquid reward and then to release the button during the intertrial interval (ITI). During each trial, after a random delay, one

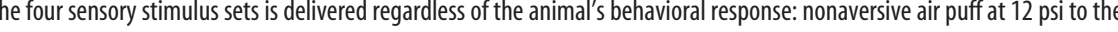
(200 $\mu \mathrm{g} / \mathrm{kg} / \mathrm{min}$ for Monkey E, 230 or $270 \mu \mathrm{g} / \mathrm{kg} / \mathrm{min}$ for Monkey H). After the start of propofol infusion, failed attempts increased for 3-4 min before LOC (magenta arrow).

two-tailed paired $t$ test $(\alpha=0.01$ ). Therefore, each neuron was classified exclusively as being puff, sound, or bimodally responsive. For population-level PSTHs, each neuron was normalized to its baseline activity and then averaged across neurons (Fig. 4C,D).

\section{Results}

Spatiotemporally distinct neuronal dynamics are associated with propofol-induced LOC

We first compared LFP spectrograms from each of the cortical areas during the transition from awake and behaving to unconsciousness. Beta oscillations were present in all three cortical areas during wakefulness $(18-25 \mathrm{~Hz}$ in $\mathrm{S} 1$ and $\mathrm{S} 2,26-34 \mathrm{~Hz}$ in PMv, Fig. 2A-D; Brovelli et al., 2004; Haegens et al., 2011). Eight to $10 \mathrm{~min}$ after propofol infusion was started, the animals underwent LOC and the spectral profiles shifted to a brief period of high-frequency broadband oscillations (lasting $\sim 3 \mathrm{~min}$ ) and subsequently to low-frequency delta and alpha oscillations. Focusing immediately around the time of LOC revealed a distinct peak in gamma-/high-beta-band power in PMv that coincided with the onset of LOC (Fig. 2E4,E5). Importantly, the increase in high-frequency power in PMv preceded that in S1. Peak power analysis indicated a frontal-to-parietal (PMv-to-S1) sequence of 
A

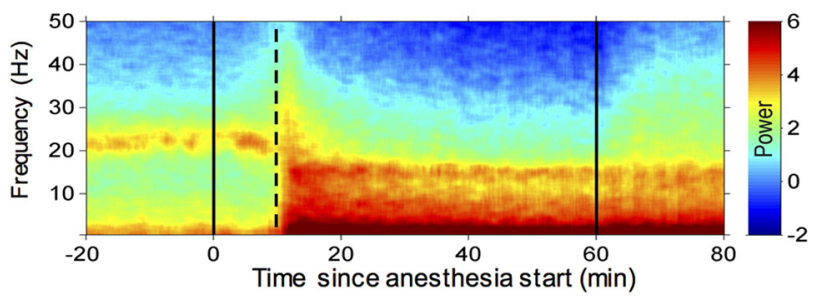

B
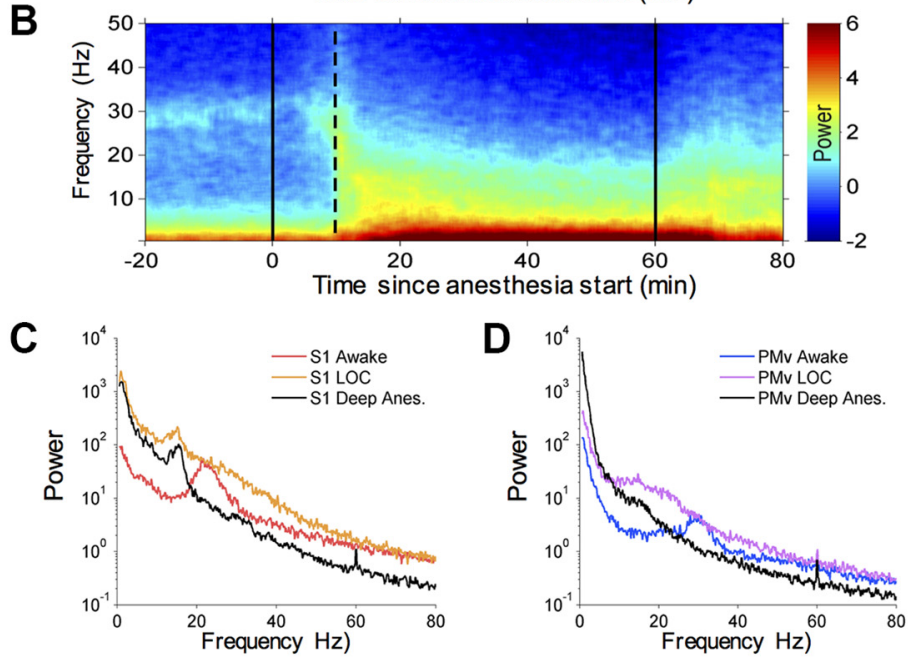

$\mathbf{F}$

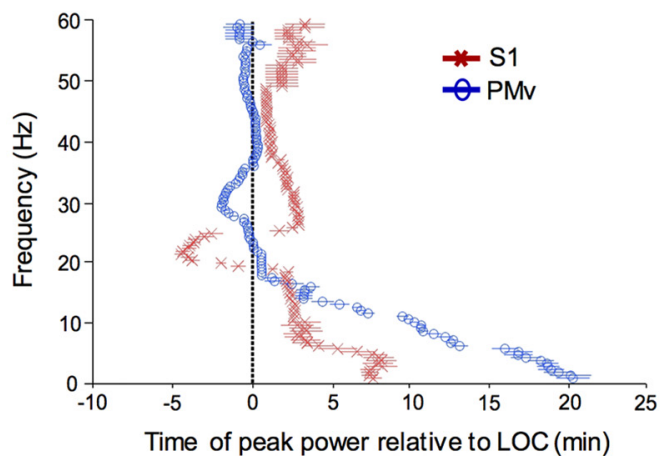

E1

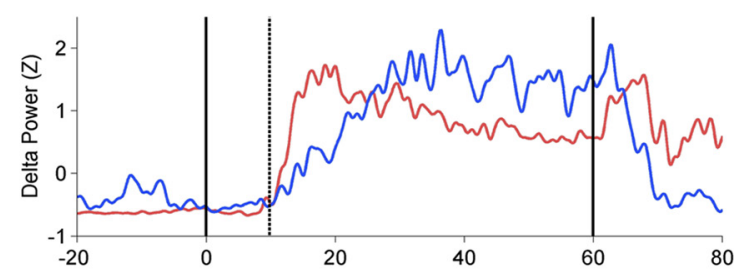

E2

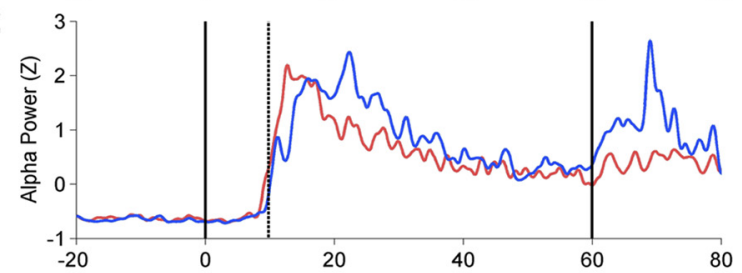

E3

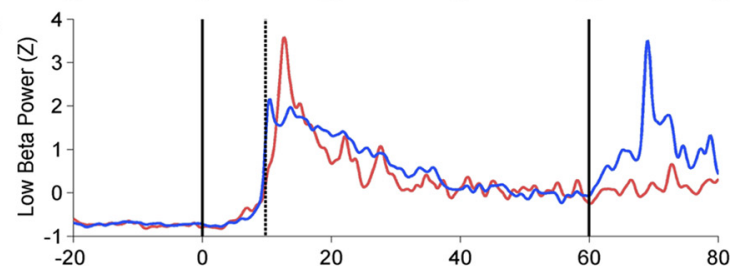

E4

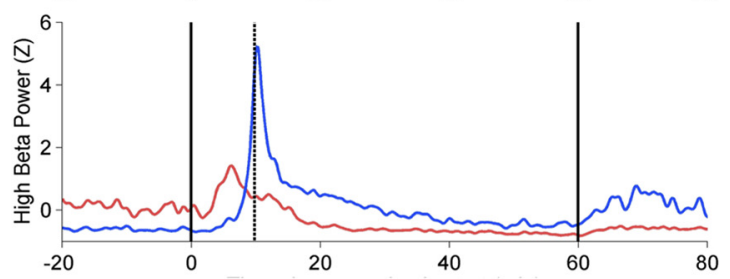

E5

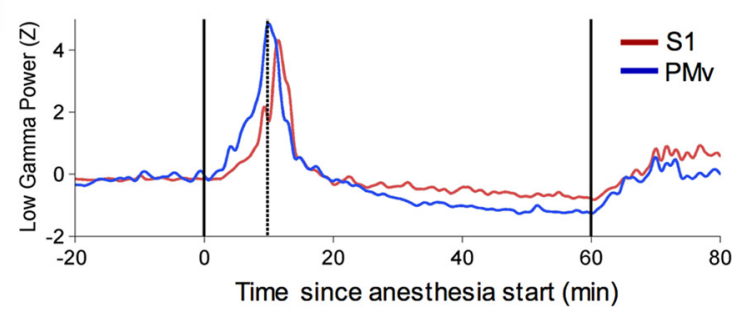

Figure 2. Brief increase in gamma/high-beta oscillations at LOC and different cortical dynamics in S1 and PMv during the time around LOC. $A, B, L F P$ spectrograms in S1 and PMv. C, D, Power spectrum in $\mathrm{S} 1$ and PMv during wakefulness and LOC versus deep anesthesia (at $40 \mathrm{~min}$ of propofol infusion). $\boldsymbol{E}$, Change in the power of different frequency bands in $\mathrm{S1}$ (red) versus PMv (blue) (normalized using Z-scores): delta (0.5-4 Hz; E1), alpha (7-12 Hz; E2), low beta (12-18 Hz; E3), high beta (18-25 Hz; E4), and low gamma (25-34 Hz; E5). $\boldsymbol{F}$, Peak power time analysis in S1 and PMv during propofol infusion. Propofol was infused from 0 to $60 \mathrm{~min}$ (black solid lines in $A, B, E$ ). LOC was detected at $10 \mathrm{~min} 26 \mathrm{~s}$ (black dotted lines in $A, B, E, F$ ).

the gamma-power peak and a parietal-to-frontal progression of the slow-frequency power (Fig. $2 F$ ), suggesting that dynamics are different between $\mathrm{S} 1$ and $\mathrm{PMv}$ in a frequency-specific manner during the time around LOC.

We next investigated how propofol affects communication across these brain regions by examining both local and regional coherence changes. We found that beta oscillations were strongly coherent between S1 and PMv during awake task performance (Fig. $3 A, B$ ). However, soon after propofol infusion was started, while the animals were still performing the task, beta coherence between $\mathrm{S} 1$ and $\mathrm{PM}_{\mathrm{V}}$ was diminished (Fig. 3C,D). The loss of coherent beta oscillations between S1 and PMv was followed by a short period of nearly complete absence of coherent activity between these regions (Fig. 3C), suggesting that functional disconnection between $\mathrm{S} 1$ and PMv precedes LOC. Diminished coherent oscillations in this network may be associated with the animal's declining performance, but not with LOC. Once LOC had been established, the slow oscillations became increasingly coherent over several minutes between these regions (Fig. 3C,E).
These sequential neurophysiological changes in the LFP power and coherence during LOC were also seen in the animals that were not required to perform any task (Fig. $5 A$ ) and in the blindfolded animals that were performing the task (Fig. 5C). These results strongly suggest that the observed neuronal dynamics were not the consequence of the animal's behavioral changes per se (i.e., cessation of task response or eye closure). Moreover, there was no comparable neurophysiological change at the loss of response in alert behaving animals (Fig. $5 E, F$ ), suggesting that loss of response due to satiety or loss of motivation is unlikely to be associated with the neurophysiological changes observed during the time around propofol-induced LOC.

\section{Cortical spiking activity changes during \\ propofol-induced LOC}

We further investigated single-neuron activity during propofolinduced altered states of consciousness. We recorded 640 well isolated single neurons from three cortical regions in two monkeys, of which $331(51.7 \%)$ were task responsive to either tactile or auditory stimulation $(n=193$ in $\mathrm{S} 1 ; n=58$ in S2; $n=80$ in 

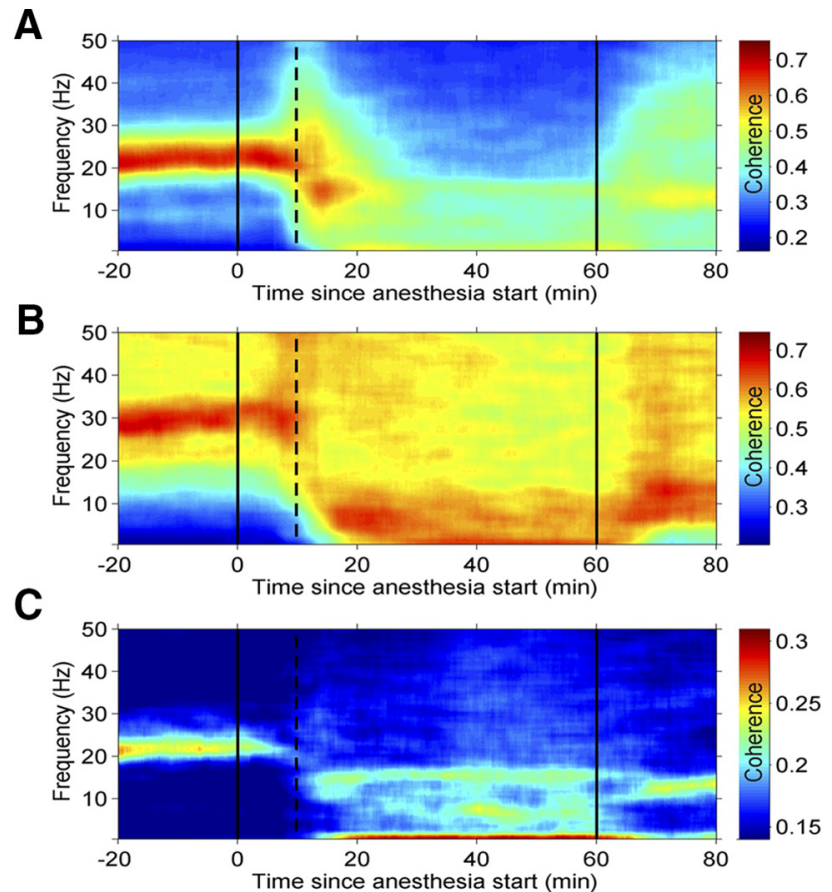

D

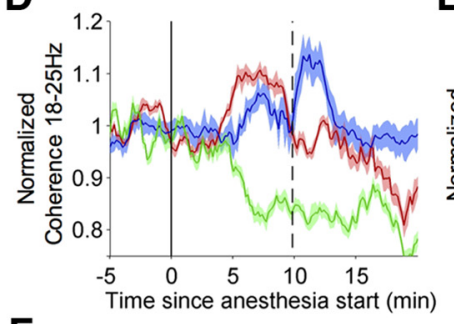

$\mathbf{F}$

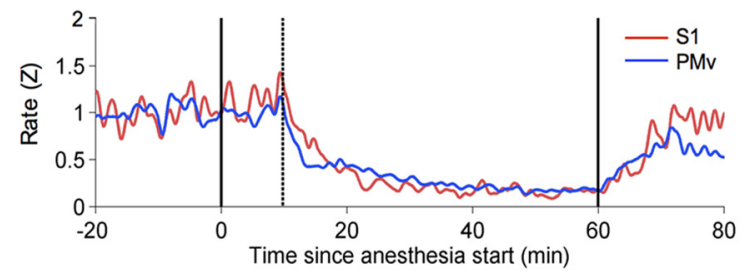

G

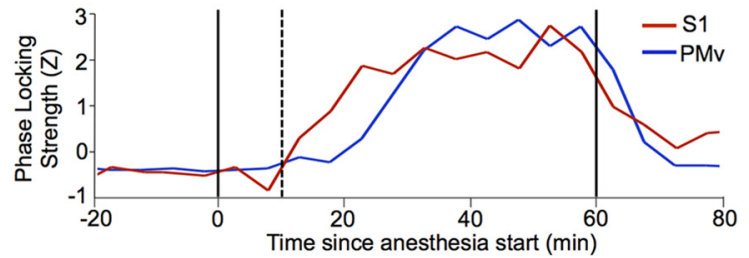

Figure 3. Disruption of intercortically coherent beta oscillations before $L O C$ and coherent slow oscillations after LOC. $A-C$, LFP coherence time-frequency plot within $S 1(A)$, PMv ( $B)$, and between S1 and PMv (C). D, Coherence change for dominant power before LOC (high beta $18-25 \mathrm{~Hz}$ ) in S1 (red), PMv (blue), and between S1 and PMv (green). Error bars indicate \pm SE. E, Coherence change for dominant power after L0C (slow oscillations $0.5-1 \mathrm{~Hz}$ ) in S1 (red), PMv (blue), and between S1 and PMv (green). Error bars indicate \pm SE. $F$, Average firing rate in S1 and PMv (normalized to preanesthetic average using Z-scores). G, Spike phase locking to delta frequency $(0.5-4 \mathrm{~Hz})$. The strength of phase locking was calculated based on the time-varying $z$-scored $\kappa$ values. Propofol was infused from 0 to $60 \mathrm{~min}$ (black lines). LOC was detected at $10 \mathrm{~min} 2 \mathrm{~s}$ (a black dotted line).

PMv). S2 neurons were recorded only from one monkey and we focused our analyses on S1 and PMv neurons. Average prestimulus firing rates were $2.3 \pm 1.9$ spikes/min in S1 and $2.6 \pm 2.2$ spikes/min in PMv (mean \pm SD). The mean neuronal firing rate was significantly decreased in both regions under propofol and the onset of the decline appeared to correspond to LOC (Fig. 3F). These changes in spike firing were seen in the animals that were not performing the task or in the blindfolded animals that were performing the task (Fig. $5 B, D$ ), suggesting that the observed spike firing changes are associated with propofol-induced LOC, but not with the loss of task response or eye closure. In addition, there was no significant change in the spike firing rate at the loss of response in alert behaving animals (Fig. $5 G$ ). After LOC, spikes were increasingly phase locked to the delta frequency during the post-LOC period (Fig. 3G), suggesting that the neurons were firing in a more synchronized fashion as the level of anesthesia deepened. The decreased firing rate and increased delta-phase locking were sustained through the end of propofol infusion and then slowly returned to preanesthetic levels.

\section{Loss of multisensory response during propofol anesthesia}

Last, we focused our analyses on sensory processing during these distinct oscillatory changes. First, we examined evoked LFP responses for puff and sound. In S1, there was a statistically significant effect of propofol-induced altered states of consciousness on puff-evoked responses $\left(F_{(3,20)}=22.3, p=1.4 \times 10^{-10}\right)$ and sound-evoked responses $\left(F_{(3,20)}=39.2, p=1.1 \times 10^{-15}\right.$; Fig. $4 A)$. Puff- and sound-evoked responses appeared to diminish toward LOC and the responses became larger and prolonged after LOC. Post-LOC-evoked responses were significantly greater than all prior responses for both puff and sound in S1 (post hoc comparison using Tukey's HSD test). In PMv, there was also a statis- tically significant effect of propofol-induced altered states of consciousness on puff-evoked responses $\left(F_{(3,5)}=12.8, p=6.8 \times\right.$ $10^{-5}$; Fig. $4 B$ ) and post-LOC-evoked responses were significantly greater than all prior responses. However, there was no statistically significant effect on sound-evoked response in PMv. We also identified distinct subpopulations of neurons on the basis of their responsiveness to the sensory stimulation during wakefulness. The PSTH analysis for each subgroup demonstrated that small but statistically significant puff responses remained under propofol in unimodal tactile neurons $\left(p=7.2 \times 10^{-15}\right.$ in $S 1, p=$ $4.1 \times 10^{-4}$ in PMv; Fig. 4C1,D1) and bimodal tactile and auditory neurons $\left(p=4.4 \times 10^{-5}\right.$ in S1, $p=0.01$ in PMv; Fig. $4 C 2, D 2)$, whereas auditory responses were nearly completely diminished under propofol. There was also a group of neurons with suppressed firing responses to both puff and sound stimulation during wakefulness and these bimodal neurons showed an enhanced firing response to tactile stimulation under propofol anesthesia (mean response difference was $-3.3 \pm 3.0 \mathrm{~Hz}$ in $\mathrm{S} 1, p=$ $0.002 ;-4.4 \pm 2.1 \mathrm{~Hz}$ in PMv, $p=6.3 \times 10^{-5}$; Fig. 4C3,D3). Together, these results suggest circuit-selective effects of propofol in multisensory processing. Further, we subcategorized neurons during wakefulness versus anesthesia independently (Fig. 4E, F, Table 1). The neuronal population summary indicates that unimodal tactile-responsive neurons and bimodal tactile and auditory-responsive neurons were both found in S1 and PMv during wakefulness. There was a larger relative distribution of bimodal neurons in PMv, consistent with their known multisensory function (Graziano and Gandhi, 2000; Lemus et al., 2009). There were a small number of unimodal sound-responsive neurons in S1 and PMv during wakefulness (PSTHs not shown in Fig. 4). In both S1 and PMv, bimodal neurons and unimodal sound-responsive neurons were diminished during propofol 
A

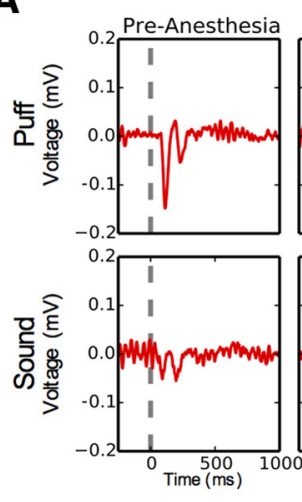

S1

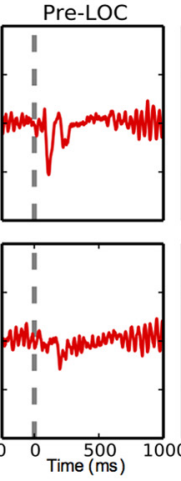

LOC
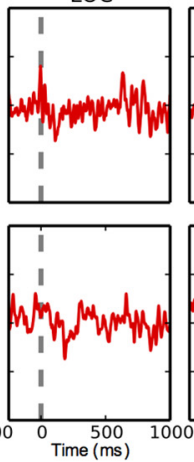

Post-LOC
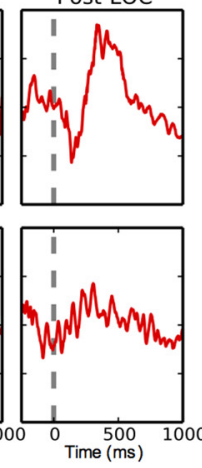

B

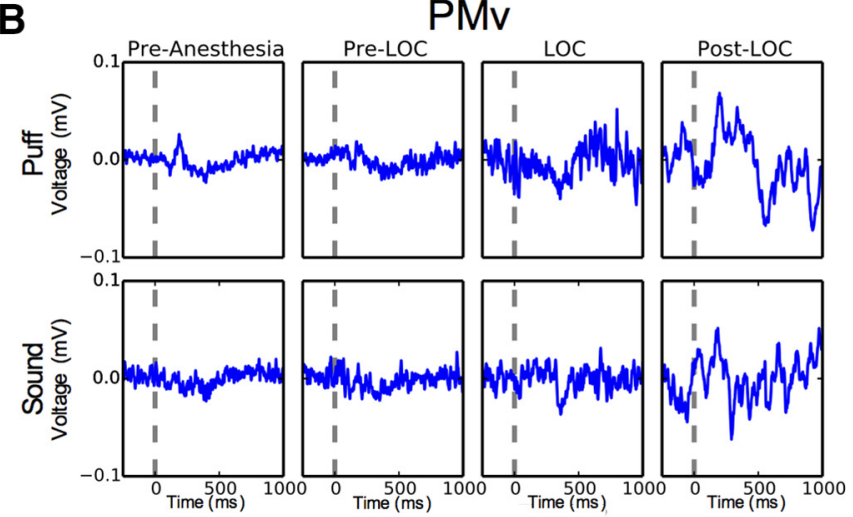

C1

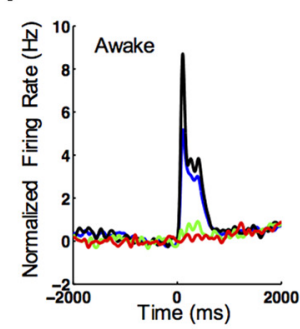

C2

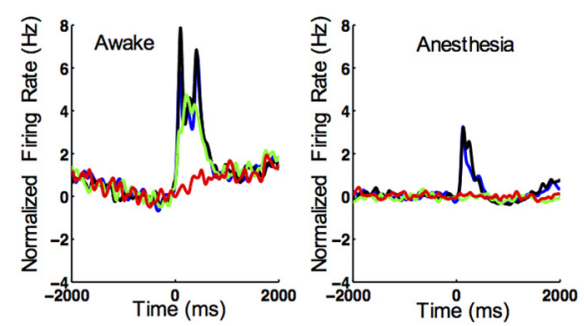

C3

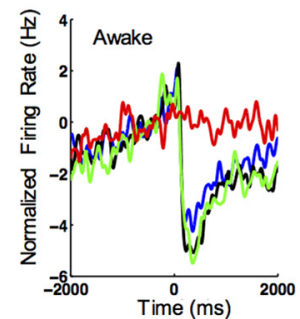

S1 Unimodal Puff

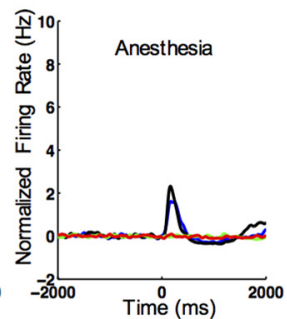

\section{D3}

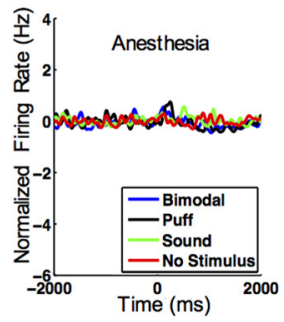

D1

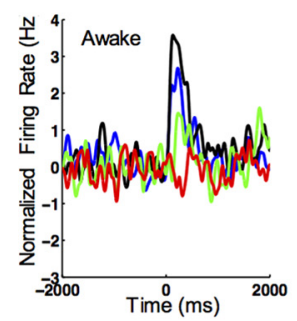

PMv Unimodal Puff

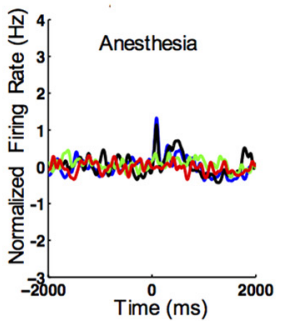

D2

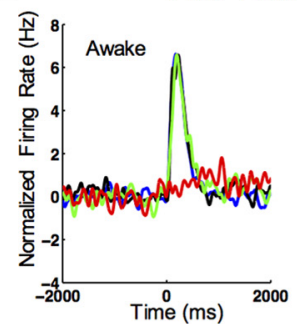

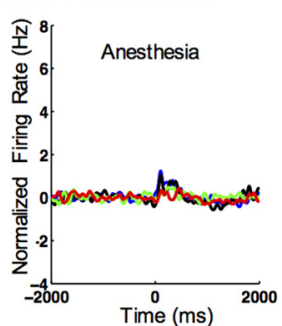

PMv Bimodal Suppressed

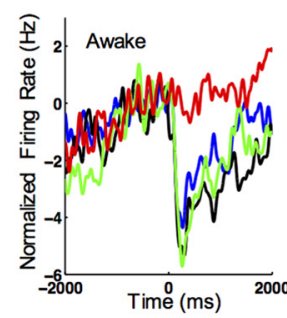

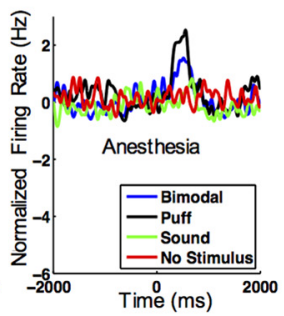

E

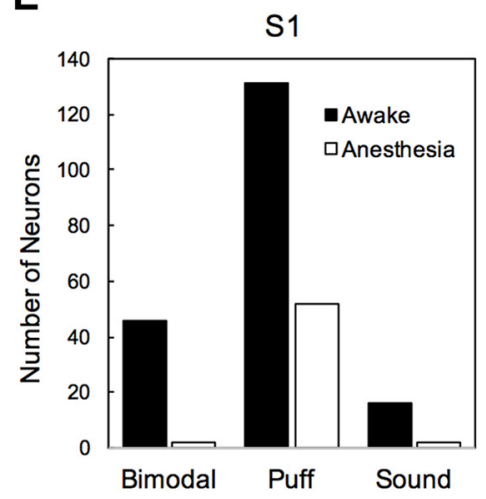

Figure 4. Sensory-evoked LFP responses and single-neuron responses in awake and anesthetized conditions. $A$, Evoked potentials (averaged for $400 \mathrm{~s}$ ) for air puff and sound in S1 during the preanesthesia, pre-LOC (after anesthesia start, before LOC), LOC, and post-LOC periods. B, Evoked potentials for air puff and sound in PMv. C, PSTHs for S1 unimodal puff-responsive neurons ( $\mathbf{C}$ ), bimodal puff and sound-responsive neurons with enhanced firing responses ( $(2)$, and bimodal puff and sound-responsive neurons with suppressed firing responses (C3) during wakefulness versus anesthesia (averaged during the last 100 trials of propofol infusion). D, PSTHs for PMv unimodal puff-responsive neurons (D1), bimodal puff and sound-responsive neurons with enhanced firing responses (D2), and bimodal puff and sound-responsive neurons with suppressed firing responses (D3) during wakefulness versus anesthesia. $\boldsymbol{E}, \boldsymbol{F}$, Population summary of three subgroups (bimodal puff and sound-responsive, puff-responsive, and sound-responsive groups) in S1 and PMv during wakefulness versus anesthesia.

anesthesia. These results indicate that the neuronal population in S1 and PMv lost their response diversity and became only responsive to tactile modality under propofol anesthesia. Awake control studies demonstrated no association between single-neuron sensory response and the animal's task performance during wakefulness (correct vs no response; Fig. $5 \mathrm{H}$ ), suggesting that loss of task response was not attributed to the observed sensory response changes under propofol in these cortical neurons.

\section{Discussion}

We found that disruption of coherent beta oscillations between $\mathrm{S} 1$ and PMv preceded, but did not coincide with, the LOC. Intercortical beta coherence diminished while animals were still performing the task and while beta oscillations were still coherent locally within S1 and PMv. Subsequently, the neuronal dynamics became different in a frequency-specific manner between these regions around the time of LOC. The observed functional discon- 
A

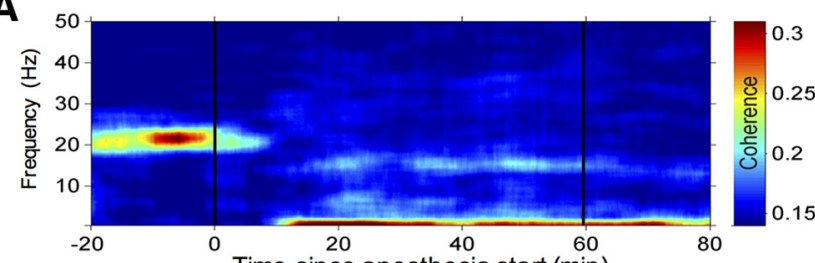

B
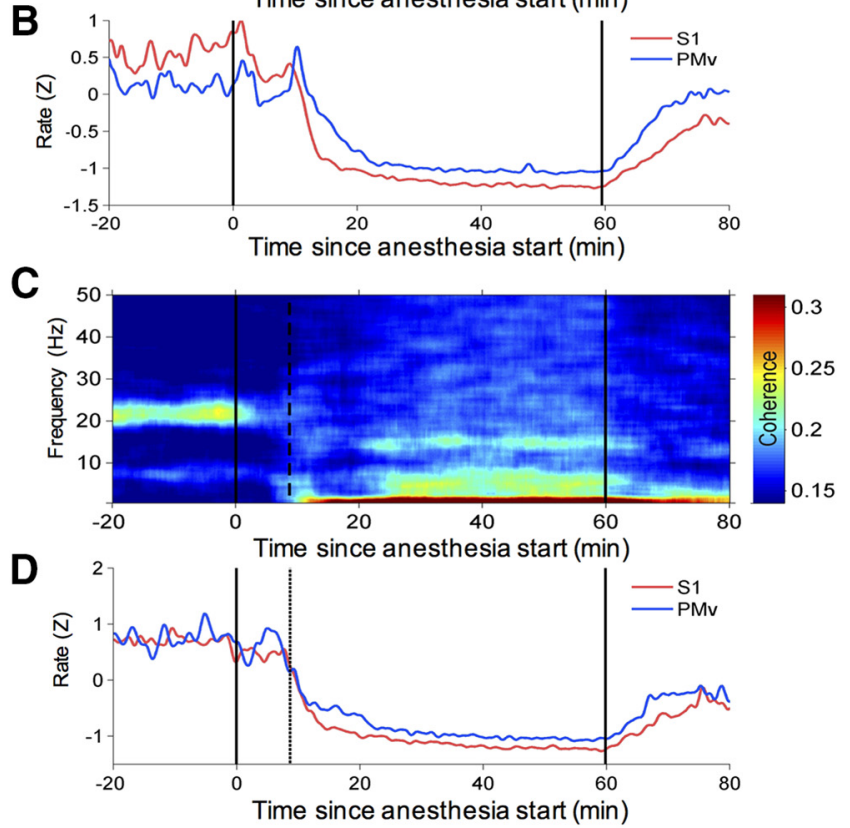

E

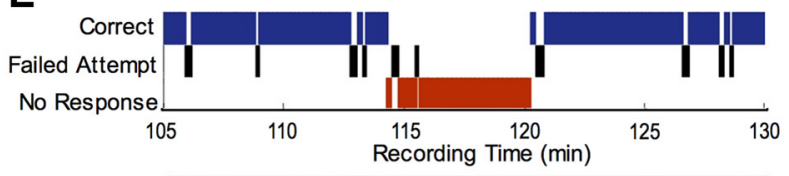

$\mathbf{F}$

G
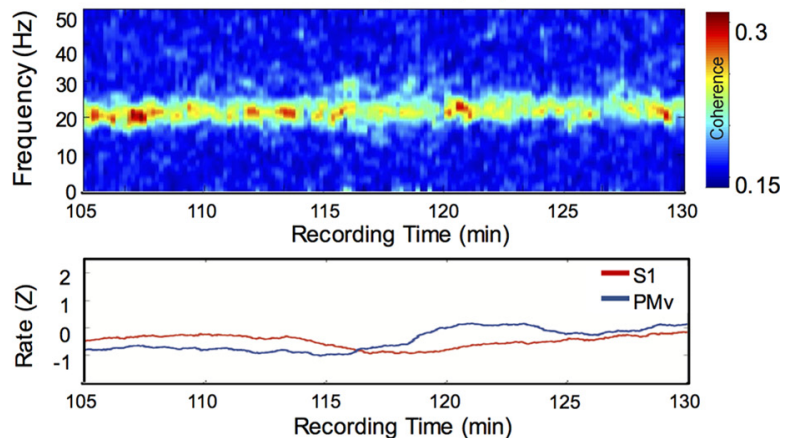

H
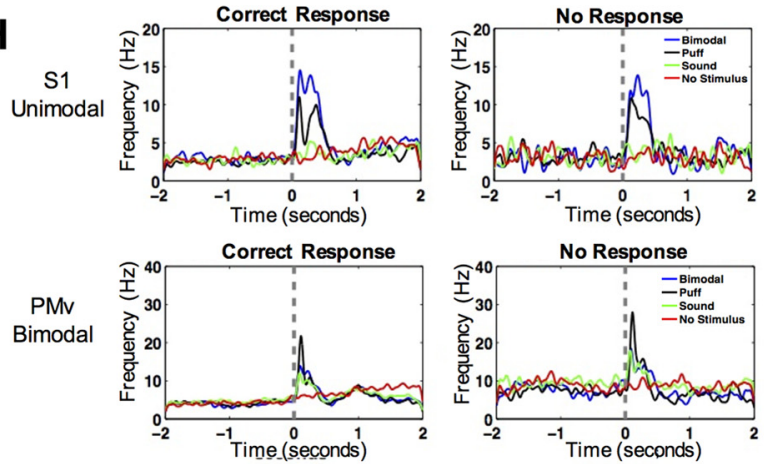

Figure 5. No task, blindfolding, and awake control studies. $\boldsymbol{A}, \boldsymbol{B}, \mathrm{LFP}$ coherence time-frequency plot between $S 1$ and PMv $(\boldsymbol{A})$ and the spike firing rate in $S 1$ and PMv ( $\boldsymbol{B})$ in an animal that was not required to perform the task. No sensory stimulation was delivered. Propofol was infused from 0 to $60 \mathrm{~min}$ (black lines). $\boldsymbol{C}, \boldsymbol{D}, \mathrm{LFP}$ coherence time-frequency plot between $S 1$ and PMv $(\boldsymbol{C})$ and the spike firing rate in $\mathbf{S 1}$ and PMv (D) in an animal that was blindfolded and performing the task. Propofol was infused from 0 to 60 min (black lines). LOC was detected at 8 min $47 \mathrm{~s}$ (a black dotted line). $\mathbf{E}-\mathbf{G}$, Behavioral responses $(\boldsymbol{E})$, LFP coherence time-frequency plot between $S 1$ and PMv $(\boldsymbol{F})$, and the spike firing rate in $\mathrm{S} 1$ and PMv $(\boldsymbol{G})$ during awake recording. Loss of response was detected at 116 min for the duration of 5 min and then the animal started responding again. $\boldsymbol{H}$, PSTHs of an $\mathrm{S} 1$ unimodal puff-responsive neuron and a PMv bimodal puff and sound-responsive neuron during awake recording. PSTHs were averaged in the four different stimulus conditions for correct trials versus no response trials.

Table 1. Number of neurons in the subgroups during wakefulness versus anesthesia

\begin{tabular}{lcclll}
\hline & $\mathrm{S} 1$ & & & $\mathrm{PMv}$ & \\
\cline { 2 - 3 } Subgroup & Awake & Anesthesia & & Awake & Anesthesia \\
\hline Bimodal enhanced & $31(16.0 \%)$ & $2(3.6 \%)$ & & $26(32.5 \%)$ & $1(5.9 \%)$ \\
Bimodal suppressed & $15(7.8 \%)$ & - & & $12(15.0 \%)$ & - \\
Unimodal puff & $131(67.9 \%)$ & $52(92.8 \%)$ & & $32(40.0 \%)$ & $15(88.2 \%)$ \\
Unimodal sound & $16(8.3 \%)$ & $2(3.6 \%)$ & & $10(12.5 \%)$ & $1(5.9 \%)$ \\
Total & 193 & 56 & 80 & 17 \\
\hline
\end{tabular}

nection before LOC may lead to regionally different dynamics by allowing these cortices to respond independently to signals through still functioning connections, including various thalamic inputs to these cortices (Zhou et al., 2011; Liu et al., 2013). Moreover, LOC appeared to correspond to a brief peak of highbeta/gamma oscillations in PMv that was followed by a gamma peak in S1. Although narrow-band gamma oscillations are known to reflect cognitive processes including attention and memory (Jensen et al., 2007; Herrmann et al., 2010), gamma activity has also been shown to increase in some unconscious states such as the rapid-eye-movement sleep (Llinás and Ribary, 1993; Steriade, 2006) and the onset of seizure activity (Lee et al., 2000). Both of these conditions are followed by slow-frequency activity, resembling the observed propofol-induced unconsciousness. Together with a recently reported gamma activity during rodent cardiac arrest (Borjigin et al., 2013), an increase in broadband gamma activity may be a common brain phenomenon during the transition to an unconscious state. The broadband gamma oscillations observed here at LOC appear to be locally coherent, but not intercortically coherent (Fig. 3A-C), suggesting that transitions to unconscious states are preceded by periods of pseudorandom activation of cell assemblies in the cortex. Whether these gamma oscillations are generated by activation of fast-spiking GABAergic interneurons at a critical propofol concentration remains to be studied (Cardin et al., 2009).

Contrary to the brief appearance of the high-beta and gamma power observed here in the LFPs, a recent human EEG study has shown that gamma and beta power remains elevated in the frontal region during the unconsciousness period under propofol (Purdon et al., 2013). The increase in the beta power is also shown as paradoxical excitation under propofol in a modeling study (McCarthy et al., 2008). Discrepancy of the temporal appearance of high-frequency oscillations between EEG and the observed LFP signals support critical decoupling of these signals (Musall et al., 2014). Once unconsciousness is established with dominant slow oscillations in both regions, the LFP signals observed here appear to be comparable to the reported EEG signals (Purdon et al., 2009; Purdon et al., 2013). Together, our results suggest that discrepancy between LFP and EEG signals can be exacerbated during the transitional state and indicate that direct LFP record- 
ing is essential to identifying the microstructure of neural activity during transition of consciousness.

After LOC, S1 and PMv became synchronized again, but the synchronization was driven by the slow oscillations and alpha/ low-beta oscillations. Slow oscillation power started to increase at the time of LOC and developed in the parietal-to-frontal direction (Fig. 2E1), an opposite direction to the appearance of the gamma power (Fig. $2 E 5, F$ ). The slow oscillations slowly increased their power to the maximum level after LOC, consistent with a recent human EEG study showing that EEG slow-wave activity rises to saturation after LOC (Ní Mhuircheartaigh et al., 2013). Likewise, spike phase locking to delta frequency slowly increased to the maximum strength. Our data suggest that the anesthetic depth under propofol can be further characterized after LOC with increasing regional coherence of the slow oscillations and their spike phase locking. Frontal delay in appearance of the slow oscillations observed here is consistent with the spatial shift of the EEG signals under general anesthesia and could be a part of what is called anteriorization (Purdon et al., 2013). This global shift has been reported repeatedly in the EEG studies (Gugino et al., 2001; John et al., 2001; Purdon et al., 2013; Vijayan et al., 2013). However, our results from the somatosensory and frontal premotor network suggest that the underlying intracortical dynamics are more complex, consisting of temporally distinct region- and frequency-specific changes.

Along with these distinct oscillatory changes, we found that sensory processing in this network also undergoes a rather discontinuous transition around LOC despite an increase in the gamma oscillations that are thought to be favorable for information transfer (Sohal et al., 2009). Prolonged evoked responses after LOC indicate decreased temporal selectivity in the synaptic response. In addition, loss of bimodal responses in the S1 and PMv neurons suggests decreased spatial selectivity during propofol anesthesia. These findings are consistent with a recent study suggesting that increased synaptic inhibitory conductance preserves high spatiotemporal selectivity during wakefulness, but the inhibitory conductance decreases under general anesthesia (Haider et al., 2013). Prolonged evoked responses, globally diminished firing rates, and decreased magnitudes of the firing responses are also consistent with the hyperpolarizing effect of propofol on neuronal membranes (Ying et al., 2006; Vijayan et al., 2013). Contrary to the hypothesis on hierarchical difference in sensory processing, our results indicate that propofol inhibits sensory responses similarly in the S1 and PMv neurons. Nevertheless, selective inhibition of auditory responses and inversion of the suppressed firing responses in these neurons suggest preferential effects of propofol on neural circuits and are consistent with an inhibition of multisensory integration.

Our results provide a direct demonstration of disruption of regional coherence preceding to LOC, coincidence of the gamma/ high-beta-power peak in PMv with LOC, and subsequent regionally different neuronal dynamics within a somatosensory and frontal premotor network during the transition from full alertness to propofol-induced unconsciousness in primates. These rather discontinuous changes in neuronal dynamics have not been demonstrated previously during the transition to LOC in a functionally interconnecting cortices, but are comparable to a recent finding of discrete metastable intermediate states during recovery of consciousness from anesthesia by Hudson et al. (2014). Our findings together suggest that a transitional state inserted between two apparently stable coherent states, such as wakefulness and unconsciousness, is not a continuous process or a single-step change, but rather a series of discrete neural activities. We also demonstrate concurrent dynamic changes in tactile and auditory processing during LOC in this network, which results in decreased spatiotemporal selectivity and preferential inhibition of auditory response, consistent with an inhibition of multisensory integration under propofol. Future use of this model will allow us to investigate whether the observed changes in neuronal dynamics during LOC are unique to the $\mathrm{GABA}_{\mathrm{A}}$ receptor-mediated propofol action or if they are common among other general anesthetics of distinct molecular mechanisms.

\section{References}

Acuña C, Pardo-Vazquez JL, Leborán V (2010) Decision-making, behavioral supervision and learning: an executive role for the ventral premotor cortex? Neurotox Res 18:416-427. CrossRef Medline

Akeju O, Pavone KJ, Westover MB, Vazquez R, Prerau MJ, Harrell PG, Hartnack KE, Rhee J, Sampson AL, Habeeb K, Gao L, Pierce ET, Walsh JL, Brown EN, Purdon PL (2014) A comparison of propofol- and dexmedetomidine-induced electroencephalogram dynamics using spectral and coherence analysis. Anesthesiology 121:978-989. CrossRef Medline

Alkire MT, Hudetz AG, Tononi G (2008) Consciousness and anesthesia. Science 322:876-880. CrossRef Medline

Asaad WF, Eskandar EN (2008a) A flexible software tool for temporallyprecise behavioral control in Matlab. J Neurosci Methods 174:245-258. CrossRef Medline

Asaad WF, Eskandar EN (2008b) Achieving behavioral control with millisecond resolution in a high-level programming environment. J Neurosci Methods 173:235-240. CrossRef Medline

Avidan MS, Jacobsohn E, Glick D, Burnside BA, Zhang L, Villafranca A, Karl L, Kamal S, Torres B, O’Connor M, Evers AS, Gradwohl S, Lin N, Palanca BJ, Mashour GA; BAG-RECALL Research Group (2011) Prevention of intraoperative awareness in a high-risk surgical population. N Engl J Med 365:591-600. CrossRef Medline

Borjigin J, Lee U, Liu T, Pal D, Huff S, Klarr D, Sloboda J, Hernández J, Wang MM, Mashour GA (2013) Surge of neurophysiological coherence and connectivity in the dying brain. Proc Natl Acad Sci U S A 110:1443214437. CrossRef Medline

Brovelli A, Ding M, Ledberg A, Chen Y, Nakamura R, Bressler SL (2004) Beta oscillations in a large-scale sensorimotor cortical network: directional influences revealed by Granger causality. Proc Natl Acad Sci U S A 101:9849-9854. CrossRef Medline

Brown EN, Lydic R, Schiff ND (2010) General anesthesia, sleep, and coma. N Engl J Med 363:2638-2650. CrossRef Medline

Brown EN, Purdon PL, Van Dort CJ (2011) General anesthesia and altered states of arousal: a systems neuroscience analysis. Annual review of neuroscience 34:601-628. CrossRef Medline

Cardin JA, Carlén M, Meletis K, Knoblich U, Zhang F, Deisseroth K, Tsai LH, Moore CI (2009) Driving fast-spiking cells induces gamma rhythm and controls sensory responses. Nature 459:663-667. CrossRef Medline

Ching S, Cimenser A, Purdon PL, Brown EN, Kopell NJ (2010) Thalamocortical model for a propofol-induced alpha-rhythm associated with loss of consciousness. Proc Natl Acad Sci U S A 107:22665-22670. CrossRef Medline

Cimenser A, Purdon PL, Pierce ET, Walsh JL, Salazar-Gomez AF, Harrell PG, Tavares-Stoeckel C, Habeeb K, Brown EN (2011) Tracking brain states under general anesthesia by using global coherence analysis. Proc Natl Acad Sci U S A 108:8832-8837. CrossRef Medline

de Lafuente V, Romo R (2006) Neural correlate of subjective sensory experience gradually builds up across cortical areas. Proc Natl Acad Sci U S A 103:14266-14271. CrossRef Medline

Graziano MS, Gandhi S (2000) Location of the polysensory zone in the precentral gyrus of anesthetized monkeys. Exp Brain Res 135:259-266. CrossRef Medline

Gugino LD, Chabot RJ, Prichep LS, John ER, Formanek V, Aglio LS (2001) Quantitative EEG changes associated with loss and return of consciousness in healthy adult volunteers anaesthetized with propofol or sevoflurane. Br J Anaesth 87:421-428. CrossRef Medline

Haegens S, Nácher V, Hernández A, Luna R, Jensen O, Romo R (2011) Beta oscillations in the monkey sensorimotor network reflect somatosensory decision making. Proc Natl Acad Sci U S A 108:10708-10713. CrossRef Medline

Haider B, Häusser M, Carandini M (2013) Inhibition dominates sensory responses in the awake cortex. Nature 493:97-100. CrossRef Medline 
Hanrahan SJ, Greger B, Parker RA, Ogura T, Obara S, Egan TD, House PA (2013) The effects of propofol on local field potential spectra, action potential firing rate, and their temporal relationship in humans and felines. Front Hum Neurosci 7:136. CrossRef Medline

Heinke W, Schwarzbauer C (2001) Subanesthetic isoflurane affects taskinduced brain activation in a highly specific manner: a functional magnetic resonance imaging study. Anesthesiology 94:973-981. CrossRef Medline

Heinke W, Fiebach CJ, Schwarzbauer C, Meyer M, Olthoff D, Alter K (2004) Sequential effects of propofol on functional brain activation induced by auditory language processing: an event-related functional magnetic resonance imaging study. Br J Anaesth 92:641-650. CrossRef Medline

Herrmann CS, Fründ I, Lenz D (2010) Human gamma-band activity: a review on cognitive and behavioral correlates and network models. Neurosci Biobehav Rev 34:981-992. CrossRef Medline

Hudetz AG (2012) General anesthesia and human brain connectivity. Brain Connect 2:291-302. CrossRef Medline

Hudson AE, Calderon DP, Pfaff DW, Proekt A (2014) Recovery of consciousness is mediated by a network of discrete metastable activity states. Proc Natl Acad Sci U S A 111:9283-9288. CrossRef Medline

Jensen O, Kaiser J, Lachaux JP (2007) Human gamma-frequency oscillations associated with attention and memory. Trends Neurosci 30: 317-324. CrossRef Medline

John ER, Prichep LS (2005) The anesthetic cascade: a theory of how anesthesia suppresses consciousness. Anesthesiology 102:447-471. CrossRef Medline

John ER, Prichep LS, Kox W, Valdés-Sosa P, Bosch-Bayard J, Aubert E, Tom M, di Michele F, Gugino LD, diMichele F (2001) Invariant reversible QEEG effects of anesthetics. Conscious Cogn 10:165-183. CrossRef Medline

Lee SA, Spencer DD, Spencer SS (2000) Intracranial EEG seizure-onset patterns in neocortical epilepsy. Epilepsia 41:297-307. CrossRef Medline

Lemus L, Hernández A, Romo R (2009) Neural encoding of auditory discrimination in ventral premotor cortex. Proc Natl Acad Sci U S A 106: 14640-14645. CrossRef Medline

Lewis LD, Weiner VS, Mukamel EA, Donoghue JA, Eskandar EN, Madsen JR, Anderson WS, Hochberg LR, Cash SS, Brown EN, Purdon PL (2012) Rapid fragmentation of neuronal networks at the onset of propofolinduced unconsciousness. Proc Natl Acad Sci U S A 109:E3377-3386. CrossRef Medline

Liu X, Lauer KK, Ward BD, Li SJ, Hudetz AG (2013) Differential effects of deep sedation with propofol on the specific and nonspecific thalamocortical systems: a functional magnetic resonance imaging study. Anesthesiology 118:59-69. CrossRef Medline

Llinás R, Ribary U (1993) Coherent 40-Hz oscillation characterizes dream state in humans. Proc Natl Acad Sci U S A 90:2078-2081. CrossRef Medline
McCarthy MM, Brown EN, Kopell N (2008) Potential network mechanisms mediating electroencephalographic beta rhythm changes during propofol-induced paradoxical excitation. J Neurosci 28:13488-13504. CrossRef Medline

Musall S, von Pföstl V, Rauch A, Logothetis NK, Whittingstall K (2014) Effects of neural synchrony on surface EEG. Cereb Cortex 24:1045-1053. CrossRef Medline

Ní Mhuircheartaigh R, Warnaby C, Rogers R, Jbabdi S, Tracey I (2013) Slow-wave activity saturation and thalamocortical isolation during propofol anesthesia in humans. Sci Transl Med 5:208ra148. CrossRef Medline

Purdon PL, Pierce ET, Bonmassar G, Walsh J, Harrell PG, Kwo J, Deschler D, Barlow M, Merhar RC, Lamus C, Mullaly CM, Sullivan M, Maginnis S, Skoniecki D, Higgins HA, Brown EN (2009) Simultaneous electroencephalography and functional magnetic resonance imaging of general anesthesia. Ann N Y Acad Sci 1157:61-70. CrossRef Medline

Purdon PL, Pierce ET, Mukamel EA, Prerau MJ, Walsh JL, Wong KF, SalazarGomez AF, Harrell PG, Sampson AL, Cimenser A, Ching S, Kopell NJ, Tavares-Stoeckel C, Habeeb K, Merhar R, Brown EN (2013) Electroencephalogram signatures of loss and recovery of consciousness from propofol. Proc Natl Acad Sci U S A 110:E1142-E1151. CrossRef Medline

Rizzolatti G, Fogassi L, Gallese V (2002) Motor and cognitive functions of the ventral premotor cortex. Curr Opin Neurobiol 12:149-154. CrossRef Medline

Romo R, Hernández A, Zainos A (2004) Neuronal correlates of a perceptual decision in ventral premotor cortex. Neuron 41:165-173. CrossRef Medline

Saleem KS, Logothetis NK (2012) A combined MRI and histology atlas of the rhesus monkey brain in stereotaxic coordinates, Ed 2. San Diego: Academic.

Sohal VS, Zhang F, Yizhar O, Deisseroth K (2009) Parvalbumin neurons and gamma rhythms enhance cortical circuit performance. Nature 459: 698-702. CrossRef Medline

Steriade M (2006) Grouping of brain rhythms in corticothalamic systems. Neuroscience 137:1087-1106. CrossRef Medline

Vijayan S, Ching S, Purdon PL, Brown EN, Kopell NJ (2013) Thalamocortical mechanisms for the anteriorization of alpha rhythms during propofol-induced unconsciousness. J Neurosci 33:11070-11075. CrossRef Medline

Ying SW, Abbas SY, Harrison NL, Goldstein PA (2006) Propofol block of $\mathrm{I}(\mathrm{h})$ contributes to the suppression of neuronal excitability and rhythmic burst firing in thalamocortical neurons. Eur J Neurosci 23:465-480. CrossRef Medline

Zar JH (1998) Biostatistical analysis, Ed 4. Upper Saddle River, N.J.: Prentice Hall.

Zhou J, Liu X, Song W, Yang Y, Zhao Z, Ling F, Hudetz AG, Li SJ (2011) Specific and nonspecific thalamocortical functional connectivity in normal and vegetative states. Conscious Cogn 20:257-268. CrossRef Medline 